\title{
OPTIMIZATION OF EXTRACTION AND STABILITY OF NATURAL COLOURS OBTAINED FROM DIFFERENT PLANT SOURCES
}

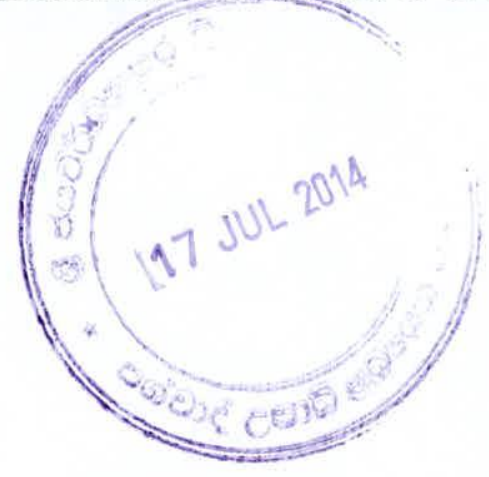

By

G. R. M. Wimalasena

This Thesis submitted in partial fulfilment of the requirements for the Degree of Masters of Food Science and Technology,

Department of Food Science and Technology,

Faculty of Applied Science,

University of Sri Jayawardenapura, Sri Lanka. 


\section{DECLARATION}

The work described in this thesis was carried by me, under the supervision of Professor K.K.D.S. Ranaweera and the report on this thesis has not been submitted in whole or in part of any University or any other institution for another Degree/ Diploma.

$24.101 / 2014$

Date

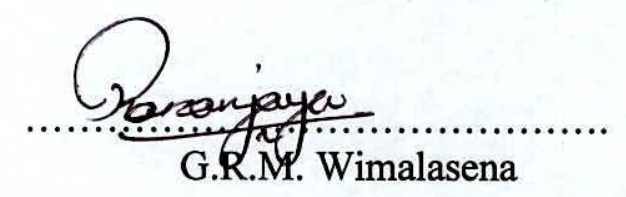


"I certify that the above statement made by the candidate is true and that this thesis is suitable for submission to the university for the purpose of evaluation"

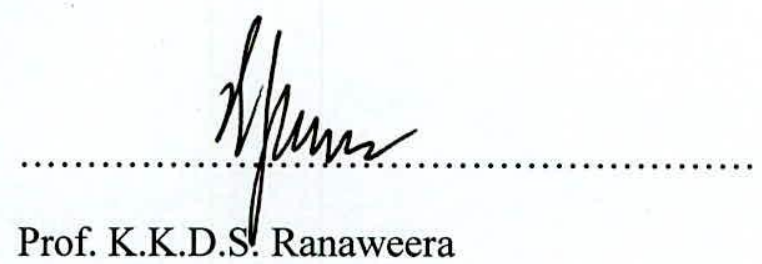

Director

Bandaranaike Memorial Ayurveda Research Institute Nawinna, Maharagama.

\section{$24 / 1-214$}

Date 


\section{THIS EFFORT IS DEDICATED TO}

MY PARENTS, ALL MY TEACHERS \&

ALL THE SUPPORTIES 


\section{TABLE OF CONTENTS}

Page.No.

Table of Content

I

List of Figures

VI

List of Tables

VIII

Acknowledgement

Abbreviations

IX

$\mathrm{X}$

Abstract

XI

\section{CHAPTER 01 INTRODUCTION}

1.1. What is a Food Colour?

1.2. Purpose of Food Colouring

1.3. Types of Food Colours

1.3.1 Artificial Food Colours

1.3.2. Natural Food Colours

2

1.4. Justification of the Study 3

1.5. Objectives of the Study

\section{CHAPTER 02 LITERATURE REVIEW}

2.1. What is Food Colour?

2.2. Distribution of Natural Pigments 5

$\begin{array}{ll}\text { 2.3. Sources of Bio-colorants } & 7\end{array}$

2.4. Classification of Colour Producing Compounds in Plants 7

2.5. Porphyrins $\quad 8$

2.5.1. Classification of Porphyrins 8

2.6. Metalloporphyrins Occurring in Nature 9

$\begin{array}{ll}\text { 2.6.1 Chlorophyll } & 9\end{array}$ 
2.6.2. Biosynthesis of Chlorophyll

2.6.3. Factors Influencing Chlorophyll Composition

2.6.4. Light absorption by Chlorophyll

2.7. Carotenoids

2.7.1. Types of Carotenoids

2.7.1.1. Carotenes

2.7.1.2. Xanthopylls

2.7.2. Structures of Carotenoids

2.7.3. Carotenoids Found in Nature 15

2.7.4. Biosynthesis of Carotenoids 15

2.7.4.1. Early Stages 15

2.7.4.2. Later Stages 16

2.7.5. Common Food Carotenoids

2.7.6. Factors that Influence the Composition of Carotenoid

2.7.7. Important Properties of Carotenoids

2.7.8. Solubility

2.7.9. Light Absorption

2.7.10. Antioxidant Properties of Carotenoids 18

2.7.11. Health Promoting Functions of Carotenoids

2.8. Flavonoids

2.8.1. Flavone

2.8.1.1. Sources of Flavones

2.8.2. Flavonol

2.8.2.1. Sources of Flavonols

2.8.3. Anthocyanin 


\section{CHAPTER 03 MATERIALS \& METHODS}

3.1. Extraction of Yellow Pigment 28

3.1.1. Carrot (Daucuscarota) 28

3.1.1.1. Extraction Using Mineral Oil and Butter 28

3.1.1.2. Extraction Using Ethanol and Petroleum Ether 28

3.1.2. Orange (Citrus sinensis) Peel 28

3.1.2.1. Extraction Using Acetone and Hexane $\quad 29$

3.1.3. Pumpkin (Cucurbita maxima) 30

3.1.3.1. Extraction Using Acetone and Hexane $\quad 30$

3.1.4. Turmeric (Curcuma longa) 31

3.1.4.1. Extraction Using Acetone and Hexane 31

3.1.4.2. Extraction Using Hexane and Petroleum Ether 32

3.1.4.3. Extraction Using Ethanol (95\%) 32

3.1.4.4. Observation of Colour Change According to $\mathrm{pH}$ Value 33 
3.2.1. Spinach (Spinaciaoleracea) 34

3.2.1.1. Extraction Using Mineral Oil and Butter 34

3.2.1.2. Extraction Using Ethanol 34

3.2.2. Grape (Vitisvinifera) 35

3.2.2.1. Extraction Using Acetic Acid 35

3.2.3. Centella(Centellaasiatica) 36

3.2.3.1. Extraction Using Ethanol and Apply into the 36 Product (Carbonated Water)

3.2.2.2. Determine Stability of Centella Extract with Maltodextrin $\quad 37$

3.2.2.3. Obtaining Centella Extract Powder by Evaporation 37

3.3. Extraction of Red Pigments 38

3.3.1. Beetroot (Beta vulgaris) $\quad 38$

3.3.1.1. Extraction Using Mineral Oil and Butter 38

3.3.1.2. Extraction Using Ethanol 38

3.3.1.3. Extraction Using Distilled Water $\quad 39$

3.3.1.3.1. Preparation of Citric Acid 40

3.3.1.3.2. Preparation of Ascorbic Acid 40

3.3.1.4. Extraction Using Ethanol and Citric Acid 40 and Apply into Carbonated Water (Soda)

3.3.1.5. Extraction Using Ascorbic Acid and 42

Citric Acid and Apply into Carbonated Water (Soda)

3.4. Extraction of Purple Pigments 43

3.4.1. Grapes (Vitisvinifera) 43

3.4.1.1. Extraction Using Mineral Oil and Butter 43

3.4.1.2. Extraction Using Water at different Temperatures 44 
3.4.1.4. Extraction Using Citric Acid and Ascorbic Acid 45

3.4.1.5. Extraction Using Acetic Acid 45

3.4.1.5.1. Evaporation of Extract to Obtain the Powder Form 46

3.4.1.5.2. Incorporate Grape Extract into Maltodextrin 47

3.4.1.6. Extraction Using Hydrochloric Acid 47

\section{CHAPTER 04 RESULTS \& DISCUSSION}

4.1. Extraction of Yellow Pigments from Carrot 49

4.2. Extraction of Yellow Pigments from Orange Peel 52

4.3. Extraction of Yellow Pigments from Pumpkin 52

4.4. Extraction of Yellow Pigments from Turmeric 53

4.5. Extraction of Green Pigments from Spinach 55

4.6. Extraction of Green Pigments from Grapes $\quad 57$

4.7. Extraction of Green Pigments from Centella $\quad 57$

4.8. Extraction of Red Pigments from Beetroot 61

4.9. Extraction of Purple Pigments 67

$\begin{array}{lll}\text { CHAPTER 05 CONCLUSION } & 74\end{array}$

$\begin{array}{ll}\text { REFERENCES } & 76\end{array}$ 


\section{LIST OF FIGURES}

Page.No.

$\begin{array}{lr}\text { 1. Molecular Structure of Porphin } & 8\end{array}$

2. Type I and Type III Porphyrin 9

$\begin{array}{ll}\text { 3. Structure of Chlorophyll a \& b } & 10\end{array}$

4. The Biosynthesis pathway of Chlorophyll 11

5. Absorption Spectra of Chlorophyll a \& b 13

6. Carotenoids Biosynthesis Pathways 16

7. Absorption spectrum of carotenoids 19

8. Molecular Structure of Flavones 21

9. Molecular Structure of Flavonol $\quad 21$

10. Molecular Structure of Anthocyanin 22

11. Biosynthesis Pathway of Flavonoids $\quad 24$

12. Colour Wheel with Wavelengths 26

13. Absorption Spectrum of Beta-carotene 51

14. Chemical Structure of Beta Carotene 53

15. Chemical Structure of Curcumin 53

16. Absorption Spectrum of Curcumin $\quad 54$

17. Absorption Spectrum of Turmeric Extract (Hexane) 54

18. Absorption Spectrum of Turmeric Extract (Ethanol) 55

19. Absorption spectrum of Chlorophyll 56

20. Absorption Spectrum of Spinach Extract 56

21. Absorption Spectrum of Centella Extract (Initial) 58

22. Absorption Spectrum of Centella Extract (after one month) 58 
23. Centella Extract with MaltodextrinAfter Drying in an Oven

24. After Evaporation of Centella Extract

25. Absorption Spectrum of Betanin

26. Absorption Spectrum of Beetroot Extract 64

27. Absorption Spectrum of Anthocyanin 69

28. Absorption Spectrum of Acetic Acid Extract of Anthocyanin 70

29. Acetic Acid Extract after Evaporation 70

30. Acetic Acid Extraction After incorporate in to the Maltodextrin 


\section{LIST OF TABLES}

Page.No

1. Classification of Colour Producing Compounds

2. Number of Double Bonds and Impart Colours of Carotenoids

3. Mean Absorbance Value Combinations of Ethanol and Citric acid

4. Mean Absorbance Value Combinations of Ascorbic Acid and Citric Acid

5. Mean Absorbance Value Combinations of Ethanol and Citric Acid Extracts

6. Mean Absorbance Value Combinations of Ascorbic Acid and Citric Acid Extracts

7. Absorbance and Yield of Citric Acid Extractions

68

8. Absorbance and Yield of Ascorbic Acid Extractions

68 


\section{ACKNOWLEDGEMENTS}

I wish to express my very sincere gratitude to my supervisor Prof. K. K. D. S. Ranaweera for his encouragement and valuable guidance extended to me throughout this project and with regard to the preparation of this thesis.

A special word of thank to all academic and non-academic members, especially $\mathrm{Mr}$. Rupasinghe, at the Department of Food Science, University of Sri Jayawardenapura for their help in various ways during the research period.

I also wish to thank all my colleagues who support me in many ways. 


\section{ABREVATIONS}

A

Conc.

${ }^{\circ} \mathrm{C}$

D

g

HCL

$\mathrm{Kg}$

M

mg

$\mathrm{ml}$

$\mathrm{nm}$

$\mathrm{NaOH}$

RT

w

$\%$

Absorbance

Concentrated

Celsius

Di pole moment

gram

Hydrochloric acid

Kilogram

Molarities

milligram

millilitres

nanometres

Sodium Hydroxide

Room Temperature

weight

Percent 


\title{
OPTIMIZATION OF EXTRACTION AND STABILITY OF NATURAL COLOURS OBTAINED FROM DIFFERENT PLANT SOURCES
}

\author{
By Gangodage Rananjaya Madushanka Wimalasena
}

\begin{abstract}
Colours are one of the widely used food additives in the present food industry. There are several purposes of the uses of colours in the food industry and the main purpose is to give an attractive appearance to the food. Food colours are mainly categorized in to two main groups, i.e Artificial and Natural. Natural colours come under three categories, namely Porphyrin, Carotenoid and Flavonoid. The present food industry is seeking opportunities and possibilities of using natural colours instead of artificial colours and simultaneously, consumers also show interest in food where natural colours have been used.
\end{abstract}

The objective of this study was to obtain natural pigments from different plant sources and study the stability of the pigments with various factors. Various types of solvents were used in the extract processes, such as ethanol, petroleum ether, hexane, $\mathrm{HCl}$, acetic acid, citric acid and ascorbic acid etc.

In yellow pigment extraction methods, turmeric extraction with $95 \%$ ethanol gave the high intensity of yellow and which had the most stability. In the green pigment extraction, Centella, ethanol extract gave the high chlorophyll extraction yield than Spinach ethanol extraction.

In the red pigment extraction, betanin in beetroot gave the high extraction yields in $20 \%$ ethanol and $0.5 \%$ citric acid extract and $0.1 \%$ ascorbic acid and $0.2 \%$ citric acid extract. These two extracts gave the betanin yield respectively $22.120 \mathrm{mg} / \mathrm{kg}$ and $28.324 \mathrm{mg} / \mathrm{kg}$. Betanin extract obtained from ascorbic acid and citric acid combination showed better stability than ethanol citric acid combination.

In the violet pigment extraction, Anthocyanin present in grape peel has a better extraction possibility in dilute acidic aqueous media. 99.7\% acetic acid and $1 \% \mathrm{HCl}$ gave the higher anthocyanin yield. The anthocyanin amount of extracts was respectively $13.39 \mathrm{mg} / 100 \mathrm{~g}$ 
and $12.397 \mathrm{mg} / 100 \mathrm{~g}$. Anthocyanin pigment extracted from both methods showed a long stability period (more than four months). 